\section{An APL program for calculating pairwise and nonpairwise a posteriori tests on means}

\author{
WILLIAM T. MCGOWAN and JAMES B. APPEL \\ Behavioral Pharmacology Laboratory \\ University of South Carolina \\ Columbia, South Carolina 29208
}

When using experimental designs with more than three treatments, an investigator is often confronted with the problem of locating mean differences following rejection of the overall null hypothesis. That is, if no specific hypotheses have been proposed in advance that are amenable to analysis by a priori procedures (e.g., orthogonal comparisons using either the $t$ or $F$ ratio), it becomes necessary to use "data snooping" procedures a posteriori (Hays, 1973; Kirk, 1968; Lindquist, 1956; Winer, 1971).

Conceptual and procedural differences between a priori and a posteriori multiple comparisons arise, in part, out of concern with error rate. That is, "Should the probability of committing a Type I error be set at $\alpha$ for each individual comparison or should the probability of an error equal $\alpha$ or less for some larger conceptual unit such as the collection of comparisons?" (Kirk, 1968 , p. 78). Conceptually, the problem is one of decision-a decision on the "conceptual unit for error rate" (e.g., individual comparison, hypothesis, family of comparisons, or the experiment). Confusion arises because, as the number of comparisons increases, so does the probability of making a false positive (Type I error) (Kirk, 1968; Ryan, 1962). Procedurally, the problem is one "of regulating and apportioning the Type I error rate" (Winer, 1971, p. 199). "For planned orthogonal comparisons, contemporary practice in the behavioral sciences favors setting the Type I error probability at $\alpha$ for each comparison. For planned and unplanned nonorthogonal comparisons it is suggested

Supported by USPHS Research Grants MH-24,593 from the National Institute of Mental Health and 9 RO1 DA 01799 from the National Institute on Drug Abuse. The authors are greatly indebted to Kirk (1968). Much, if not most, of the present discussion follows directly from Kirk's excellent exegesis of both a priori and a posteriori multiple-comparison procedures. Without his work the present paper would not have been possible. We are also indebted to Mr. Charles Poole of the Computer Services Division, University of South Carolina, for his technical advice and for access to computer facilities and to Dr. James Laughlin, Department of Psychology, University of South Carolina, for his helpful advice and critical reading of the manuscript. that the Type I error probability should be set at $\alpha$ for the collection of comparisons" (Kirk, 1968, p. 78). Several a posteriori multiple-comparison procedures exist which enable an investigator to set the Type 1 error probability equal to or less than $\alpha$ for the collection of comparisons. Familiarity with these a posteriori procedures is assumed, and the present discussion will be limited to a method by which these tests may be easily calculated. Kirk (1968) offers an excellent review of a posteriori procedures; the work of Hays (1973) and Winer (1971) complement that of Kirk. Use of the method (computer program) discussed below should result in substantial time savings, the alleviation of computational difficulties, and greater flexibility in choice of a posteriori tests.

The present paper describes a computer program (APL) that can be used to compute several commonly used a posteriori multiple-comparison tests: (1) NewmanKeuls, (2) Duncan's new multiple-range (NMR) test, (3) Tukey's honestly significant difference, Type a [h.s.d.(a)], (4) Tukey's honestly significant difference, Type b [h.s.d.(b)], (5) Fisher's least significant difference (1.s.d.) test, (6) Dunn's procedure (also know as the Bonferroni t statistic, and (7) Scheffe's method. Each of these tests is described in detail by Kirk (1968) with the exception of Tukey's Type b test, which is described by Winer (1971).

The a posteriori multiple-comparison APL program is written "interactively" (conversationally) and is intended for users who are only vaguely familiar with APL. It is presented in Table 1 and explained below.

Function 1: RBD. RBD is a function (fns) used in the analysis of a randomized block design, that is, a mixed model in which subjects (blocks) represent a random effect and treatments represent a fixed effect. Fns RBD, the output of which is a summary ANOVA table, is used to illustrate the a posteriori multiplecomparison APL program described herein. All that is necessary to use the fns is to type the name of the fns (RBD), followed by a space, and then the name of the data set. The data set may be built easily through the use of the general-purpose data building fns BUILDMTX, described by McGowan and Appel (1977). For illustrations of the use of fns RBD, see Table 2.

Function 2: POSTHOC. The purpose of fns POSTHOC is to build left and right arguments for fns APPC and ANPC (below) and to organize the necessary fns for the a posteriori analysis. To use the fns, one must type the name POSTHOC and respond appropriately to the queries (Qs) generated by the fns. The first query (Q-1) requests the type of a posteriori test desired (a posteriori select value). A response of any real number between one and nine will "select" the respective a priori test; "zero" causes a listing of all the available a posteriori tests to be printed with their respective 
TABLE 1

Fns I RBD

$\nabla R B D X V$

[1] ARANDOMIZED BLOCK DESIGN

[2] AMIXED MODEL [SUBJECTS $=$ RANDOM; TREATMENTS $=$ FIXED]

[3] $V+1$,

[4] $S S T+(B S++/,(X V * 2))-(X+((+/, X V) * 2) *((Q+1+\rho X V) \times(N+1+\rho X V)))$

[5] $\quad M S B+(S S B+(S B+(+/(((+/[1] \times V) * 2)+N)))-X)+(D F B+Q-1)$

[6] $M S S+(S S S+(S S+(+/(((,+/ X V) * 2) \div Q)))-X) \div(D E S+N-1)$

[7] $M S R+(S S R+((B S-S B)-S S)+X) \div(D F R+(N-1) \times(Q-1))$

[8] $\quad 2 B A R+(+/[1] X V)+N$

[9] $(25 \rho \mathrm{V})$, 'ANALYSIS OF VARIANCE TABLE'

[10] (190V),'RANDOMIZED BLOCK DESIGN: MIXED MODEL'

[11] $175 \rho^{\prime}-1$

[12] $(4 \circ V), ' S O U R C E^{\prime},(19 \rho V), ' S S^{\prime},(10 \rho V), ' D F^{\prime},(12 \rho V), ' M S^{\prime},(11 \rho V), F^{\prime}$

[13] $175 \rho^{\prime}-1$

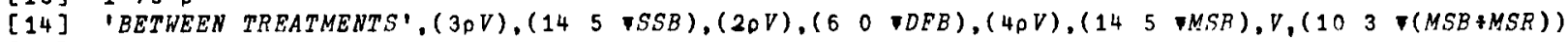

[15] $V$

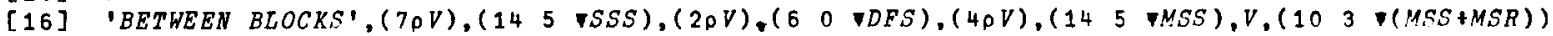

[17] $V$

[18] (4คV), 'RESIDUAL'

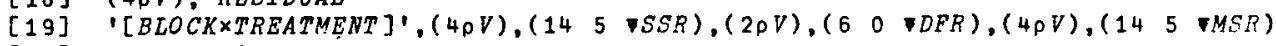

[20] $175 \rho^{\prime}-$

[21] 'TOTAL', $(16 p V),(145$ TST $),(2 p V),(6 \quad 0 \quad(Q \times N)-1)$

[22] $175 \rho^{\prime-1}$

Fns II POSTHOC

$\nabla$ POSTHOC;AS;C;C;V

[1] $C+\cdots$

[2] $\quad \mathrm{C}+10 p(\mathrm{~V}+1 \mathrm{I})$

[3] UP1:'TYPE A POSTERIORI SELECT VALUE [0=LISTING]'

[4] $\rightarrow D N 1 \times 1(A S+\square)=0$

[5] 'TYPE: 1) MEAN SQUARE ERROR, 2) COMPARISON SAMPLE SIZE'

[6] $N P+[], A S$

[7] 'TYPE HEAN VALUES OR VARTABLE MEAN NAME'

[8] $Z B A R+1]$

[9] NP APPC ZBAR

$[10] \rightarrow 0$

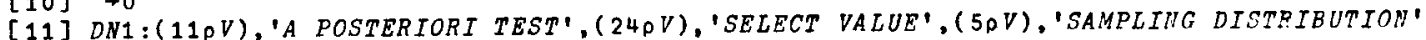

[12] $90 \rho^{\prime-1}$

[13] 'NEWMALI-KEULS', (46DV), '1', C, STUDENTIZED RANGE'

[14] 'DUNCAN',C 'S NEH MULTIPLE RANGE [NMR]',(250V),'2',C, 'DUNCAN',C, 'S QR'

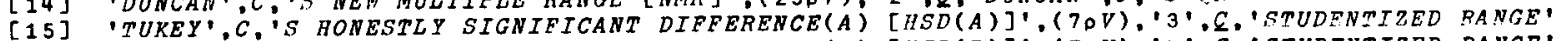

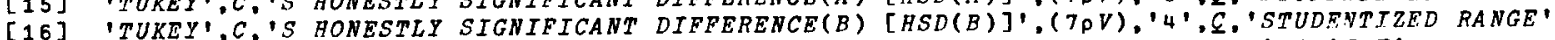

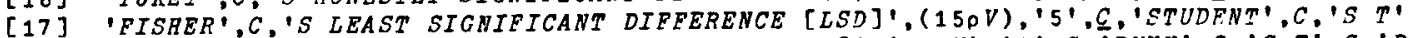

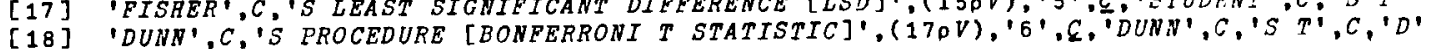

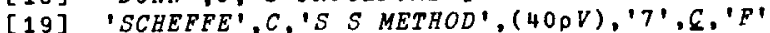

[20] 'SCHEFEE',C, 'S PROCEDURE [PAIRWISE/NONPAIRWISE]',(160V), '8',C.' ${ }^{\prime}$ '

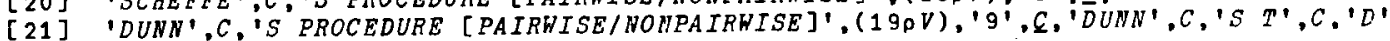

[22] $90 p^{\prime}-1$

$[23] 21 \rho V$

[24] $\rightarrow U P 1$

Fns III APPC

$\nabla N P \quad A P P C \quad 2 B A R ; C ; D ; G ; I ; I A ; I B ; M S ; N ; N H ; Q ; T ; Z ; V ; V ; W ; Z$

[1] $M S+N P[I A+I+1]$

[2] $I B+\phi(1(N+\rho Z B A R))$

[3] $Z+\triangle Z B A R$

[4] $C+1+1$

[5] $\mathrm{V}+1$,

[6] $\rightarrow(D N 10, D N 10, D N 6, D N 5, D N 4, D N 3, D N 3, D N 2, D N 1)[(9,8,7,6,5,4,3,2), N P[3]]$

[7] DN1:NH+'NEWMAN-KEULS'

[8] 'TYPE Q VALUES FOR NEWMAN-KEULS TEST $[R=2-1 ; N ; '] '$

[9] $\rightarrow D N 7$

[10] DN2:NH+'DUNCAN',C, 'S NMR TEST'

[11] 'TYPE O VALUES FOR DUNCAN',C, 'S TEST $\left[R=2-^{\prime} ; N ; '\right]$ '

[12] $\rightarrow$ DN7

[13] DN3:NH+'TUKEY',C, 'S HSD(A) TEST'

[14] TYYPE Q/K VALUE FOR TUKEY',C,'S HSD TEST $[K=1 ; n ; ']$ '

$[15] \rightarrow D N 7 \times 1 N P[3]=3$ 
TABLE 1 (continued)

[16] $Q+U$

[17] NH+'TUKEY',C,'SHSD(B) TEST'

[18] 'TYPE Q/R VALUES FOR TUKEY',C,'S HSD TEST $\left[R=2-' ; N ;{ }^{\prime}\right]$ '

[19] $Q+(Q+[) \div 2$

$[20] \rightarrow D N 8$

[21] DN4:NH+'FISHER',C, 'S LSD TEST'

[22] 'TYPE T VALUE FOR LSD TEST [a/2]'

$[23] \rightarrow D N 7$

[24] DNS:NH+'DUNN',C,'S PROCEDURE'

[25] 'TYPE T VALUE FOR DUNN',C. 'S TEST $\left[C={ }^{\prime} ;(0.5 \times(N \times(N-1))) ;{ }^{\prime}\right] '$

$[26] \rightarrow D N 7$

[27] DN6:NH+'SCHEFFE',C,'S S METHOD'

[28] 'TYPE F VALUE FOR SCHEFFE',C, S TEST $[K=1 ; N ; '] '$

[29] DN7:Q* ]

[30] $2(N P[3] \epsilon 5,6,7) / ' M S+2 \times N P[1] '$

[31] $2(N P[3]=7) /, Q+(((N-1) \times Q) * .5) '$

[32] $D N 8: H+(N, N) D(((N, S \div N P[2]) * 0.5) \times Q)$

[33] $(N P[3] \epsilon(2) / W+(N, N) D(0,(((N S+N P[2]) * .5) \times Q)) \prime$

[34] $D+400^{\prime}-1$

[35] $T+(T+-((\$ 2)-(2+(N, N) \circ(Z B A R[Q Z R A R]))))>W$

[36] 'MULTIPLE COMPARISON: , NH

[37] $D$

[38] 'SIGNIFICANT CONTRAST',(10pV), 'DIFEERENCE'

[39] $D$

$[40]$ UP $1: \rightarrow D N 9 \times_{1}(+/ T[I ;])=0$

[41] $G+\phi(T[I ;] / Y)$

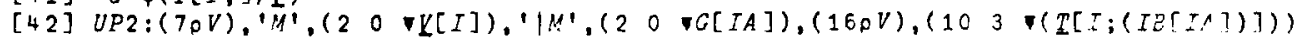

$[43] \rightarrow U P 2 \times 1(I A+I A+1) \leq D C$

[44] $\rightarrow U P 1 \times 1(I+I+(I A+1))<N$

[45] DN9:D

[46] $\rightarrow 0$

[47] DN10:NP ANPC ZBAR

Fns IV ANPC

$\nabla N P$ ANPC $2 B A R ; A ; A 1 ; A 2 ; A 3 ; A 4 ; C ; C ; C C ; C C ; C V ; I ; I M ; Q ; M ; M T X ; N X ; N ; N C ; N H ; X P ; S ; S V ; T C ; V$

[1]

$[2]$

[3]

$[4]$

[5]

[6]

$[7]$

$[8]$

[9]

[10]

[11] DN1:NR+'SCHEPFE',C, 'S PROCEDURE
[12] 'TYPE F VALUE FOR SCAEFFE', C, 'S

[13] $Q+(((N-1) \times \square) \star 0.5)$

[14] DN2: $\rightarrow D R 3 \times 1 \pi P[2]=0$

[15] 'TYPE SAMPLE SIZE POR EACH TREATMENT'

[16] $\quad N P+\square$

[17] DN3:'TYPE MEAN INDEXES [C-1; I;']'

[18] $I M+\square$

[19] 'TYPE CONTRAST COERFICIENTS [C-';I;']'

$[20] \quad C V+Q \times((N P[1] \times(+/(((C C+C C+Q) * 2)+B P[I M]))) * 0,5)$

[21] $\quad 2((\mid(T C++/(C C \times(2 B A R[I M]))))>C V) / S V+S '$

[22] $M X+,\left(\left((C, 1) p^{\prime} M^{\prime}\right),(20,(C, 1) p I M),((C, 1) p((((C+p I M)-1) p \cdot 1), V))\right)$

[23] $(I=1) / A 3+(A 1+p M X)+(A 2+p C E)+47^{\prime}$

$[24] M T X+(((A 1-(\rho M X))+5) \rho V), M X,(((A 2-(p C E))+10) \rho V), Q C,(7 p V),(103 \nabla T C),(13 \rho V), S V$

$[25] \rightarrow D N 5 \times 1(O M T X)>100$

[26] $M[I ;]+(M T X,(100-(\rho M T X)) \rho(S V+V))$

$[27] \rightarrow D N 3 \times 1(I+I+1) \leq N C$

[28] (5PV), MULTIPLE COMPARISON: 'NH

[29]: $A+(1,100) \rho\left((5 \rho V),\left((A 3) \rho^{\prime}-1\right),((100-(A 3+5)) \rho V)\right)$

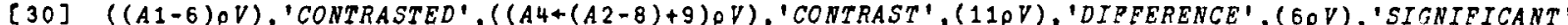

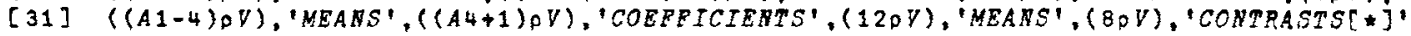

[32] $A,[1](O M),[1] A$

$[33] \rightarrow 0$

[34] ON5:'CHARACTER LINE > 100 CHARACTERS[';OM;']: ADJUST FORMAT' 
TABLE 2

RBD

\begin{tabular}{rllll} 
XVAR & \multicolumn{3}{l}{} \\
67.24 & 93.3 & 85.71 & 94.69 & 75.36 \\
65.36 & 93.75 & 83.93 & 93.31 & 77.84 \\
69.84 & 96.41 & 80.8 & 96.43 & 72.77 \\
66.36 & 94.86 & 79.46 & 92.76 & 73.66 \\
68.42 & 93.33 & 80.66 & 95.46 & 74.44 \\
67.27 & 95.17 & 84.32 & 94.89 & 76.89
\end{tabular}

$R B D \quad X V A R$

ANALYSIS OF VARIANCE TABLE RANDOMIZED BLOCK DESIGN: MIXED MODEL

\begin{tabular}{|c|c|c|c|c|}
\hline SOURCE & $S S$ & $D F$ & $M S$ & $F$ \\
\hline BETWEEN TREATMENTS & 3422.16348 & 4 & 855.54087 & 272.920 \\
\hline BETWEEN BLOCKS & 16.27739 & 5 & 3.25548 & 1.039 \\
\hline $\begin{array}{c}R E S I D U A L \\
{[B L O C K \times T R E A T M E N T]}\end{array}$ & 62.69536 & 20 & 3.13477 & \\
\hline TOTAL & 3501.13623 & 29 & & \\
\hline
\end{tabular}

$Z B A R$

$67.41594 .47 \quad 82.48 \quad 94.59 \quad 75.16$

TABLE 3

POSTHOC

Example 1: a) A posterfor1 select values, b) Newman-Keuls

POSTHOC

TYPE A POSTERIORI SELECT VALUE [O=LISTING]

Q:

0

A POSTERIORI TEST

$S E L E C T$ VALUE

SAMPLING DISTRIBUTION

NEWMAN-KEULS

DUNCAN'S NEN MULTIPLE RATGE [NMR]

TUKEY'S HONESTLY SIGNIFICANT DIFFERENCE(A) [BSD(A)]

TUKEY'S HONESTLY SIGNIPICANT DIFFERENCE $(B)[H S D(B)]$

RISHER'S LEAST SIGNIFICANT DIFRERENCE [LSD]

DUNN'S PROCEDURE [BONRERRONI T STATISTIC]

SCEEREE'S S METHOD

SCHERFE'S PROCEDURE [PAIRWISE/NONPAIRWISE]

DUNR'S PROCEDURE [PAIRWISE/HONPAIRWISE]

$\begin{array}{ll}1 & \text { STUDENTIZED RANGE } \\ 2 & \text { DUNCAR'S QR } \\ 3 & \text { STUDENTIZED RANGE } \\ 4 & \text { STUDENTIZED RANGE } \\ 5 & \text { STUDENT'ST } \\ 5 & \text { DUNN'ST'D } \\ 7 & F \\ 8 & F \\ 9 & \text { DUNN'S T'D }\end{array}$

TIPE A POSTERIORI SELECT VALUE [0=LISTING]

]:

1

TYPE: 1) MEAN SQUARE ERROR, 2) COMPARISON SAMPLE SIZE

0:

3.1356

TYPE MEAR VALUES OR VARIABLE MEAN NAME

प:

$67.41594 .47 \quad 82.48 \quad 94.5975 .16$

TIPE Q VALUES POR NEWMAN-KEULS TEST [R=2-5]

व:

$\begin{array}{llll}4.02 & 4.64 & 5.02 & 5.29\end{array}$ 
TABLE 3 (continued)

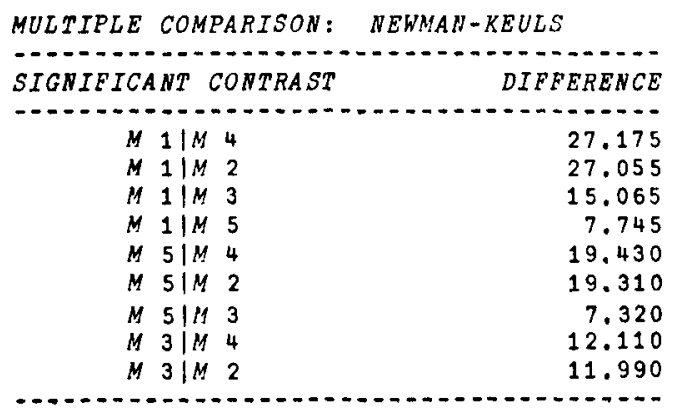

Example 2: a) Varlable mean name, b) Duncan's NMR test

POSTHOC

TYPE A POSTERIORI SELECT VALUE [0=LISTING]

D:

2

TYPE: 1) MEAN SQUARE ERROR, 2) COMPARISON SAMPLE SIZE

口:

3.1356

TYPE MEAR VALUES OR VARIABLE NEAR RAME

D:

$2 B A R$

YPE Q VALUES FOR DUNCAN'S TEST [R=2-5]

$\mathrm{O}$ :

$\begin{array}{llll}4.02 & 4.22 & 4.33 & 4.40\end{array}$

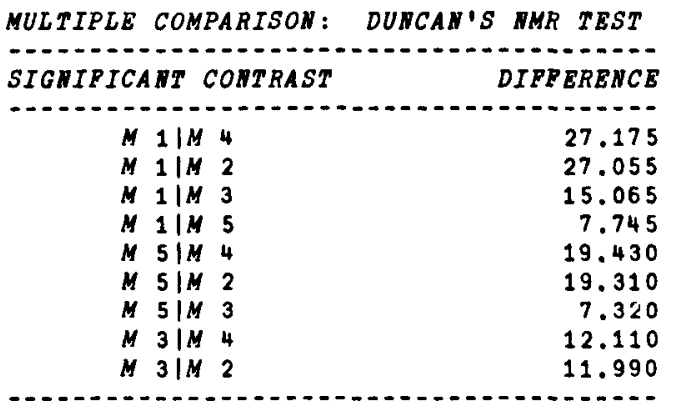

select values and the appropriate table to enter (see Example 1 in Table 3). After the printout, Q-1 is repeated and the desired a posteriori test may be chosen by typing the appropriate select value. Q-2 requests first the appropriate mean square error term (Kirk, 1968), and then the comparison sample size. Only a single value is typed in response to the comparison sample size, either the $\mathrm{n}$ corresponding to any given treatment level when ns are equal (a posteriori Tests 1.7) or a zero when the ns are unequal (a posteriori Tests 8-9). A zero response causes the program to generate the necessary $\mathrm{Q}$ later. Fns POSTHOC organizes responses Q-1 and Q-2 into vector NP; the first element equals the mean square error term; the second, the comparison sample size; and the third, the a posteriori select value. Vector NP is the left argument of fns APPC and ANPC (below). The final Q (Q-3) generated by fns POSTHOC requests mean values. Either the variable mean name is typed in response to Q-3 (i.e., mean vector has already been formed) or the value of each treatment mean is typed.
The mean vector (ZBAR) is the right argument of fns APPC and ANPC (below). For illustrations of fns POSTHOC, see Table 3.

Function 3: APPC. Only pairwise contrasts on means are calculated within fns APPC. Equal ns are required for all treatment levels. Fns APPC has both left (NP) and right (ZBAR) arguments (above) and can be used alone or in combination with the calling fns POSTHOC. APPC generates a single $Q-a$ request for the value of the test statistic (e.g., Students t distribution, F distribution, or Dunn's t'D distribution). The degrees of freedom for the statistic is that associated with the appropriate error term. The fns generates as an aid (reminder) in entering the appropriate tables: the values of $k$, the number of treatments (number of elements in ZBAR); $r$, the number of steps separating ordered means (range of elements in ZBAR); or $\mathrm{c}$, the number of contrasts $[(\mathrm{k}(\mathrm{k}-1)) \div 2]$.

Output of fns APPC is a table organized into two columns. The first column gives all the significant 


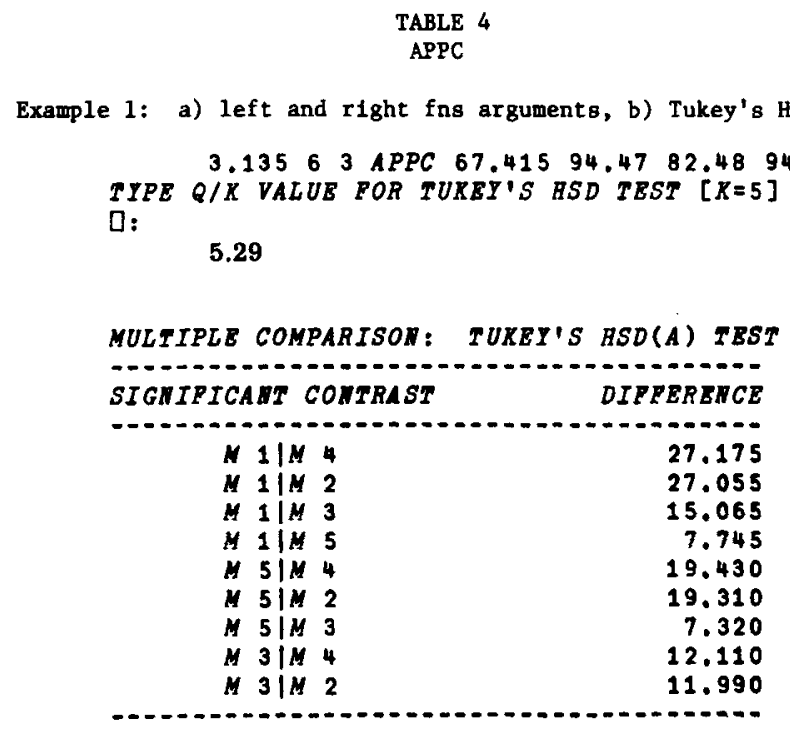

Example 2: a) left and right arguments, b) Tukey's HSD(B) test

Example 4: a) Dunn's procedure

3.13564 APPC $Z B A R$

TYPE Q/X VALUE POR TUKEY'S BSD TEST [ $\mathrm{K}=5]$

D:

5.29

TYPE Q/R VALUES BOR TUKEY'S ZSSD TEST [R=2-5] D:

$\begin{array}{llll}4.02 & 4.64 & 5.02 & 5.29\end{array}$

$3.1356 \quad 6$ APPC ZBAR

TYPE T VALUE FOR DUNN'S TEST [C=10]

Q:

$\mathbf{3 . 8 5}$

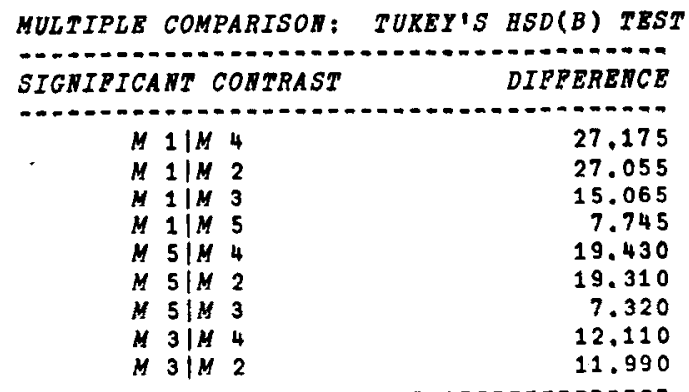

MULTIPLE COMPARISON: DURN'S PROCEDURE

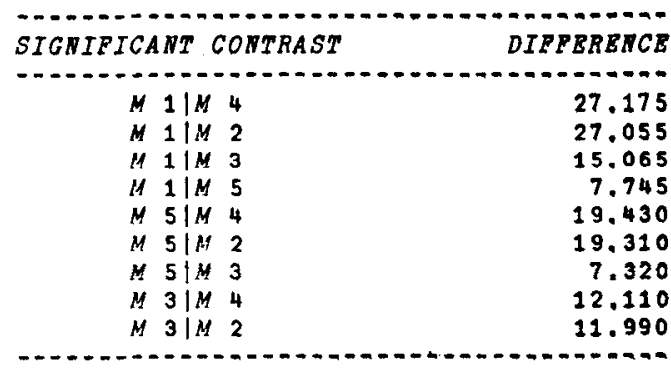

Example 3: a) F1sher's LSD test

3.13565 APPC $Z B A R$

TIPE T VALDE FOR LSD TEST [ $\alpha / 2]$

प:

2.845

Example 5: a) Scheffé's $S$ method

3.13567 APPC 2BAR

TYPE P VALUE FOR SCHEFFE'S TEST [K=5]

प:

$$
4.43
$$

NULTIPLE CONPARISON: PISHBR'S LSD TEST

MULTIPLE COMPARISON: SCEERFE'S S METHOD

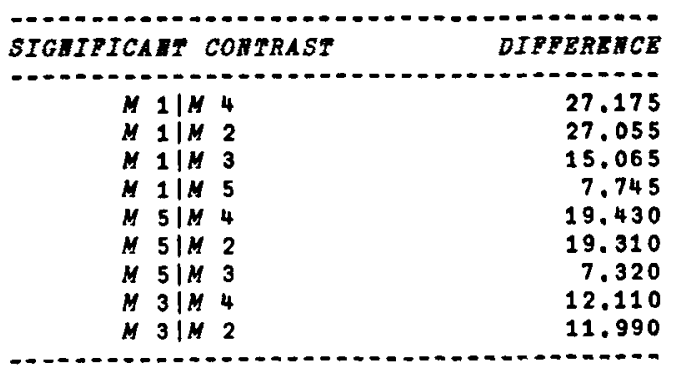


TABLE 5

ANPC

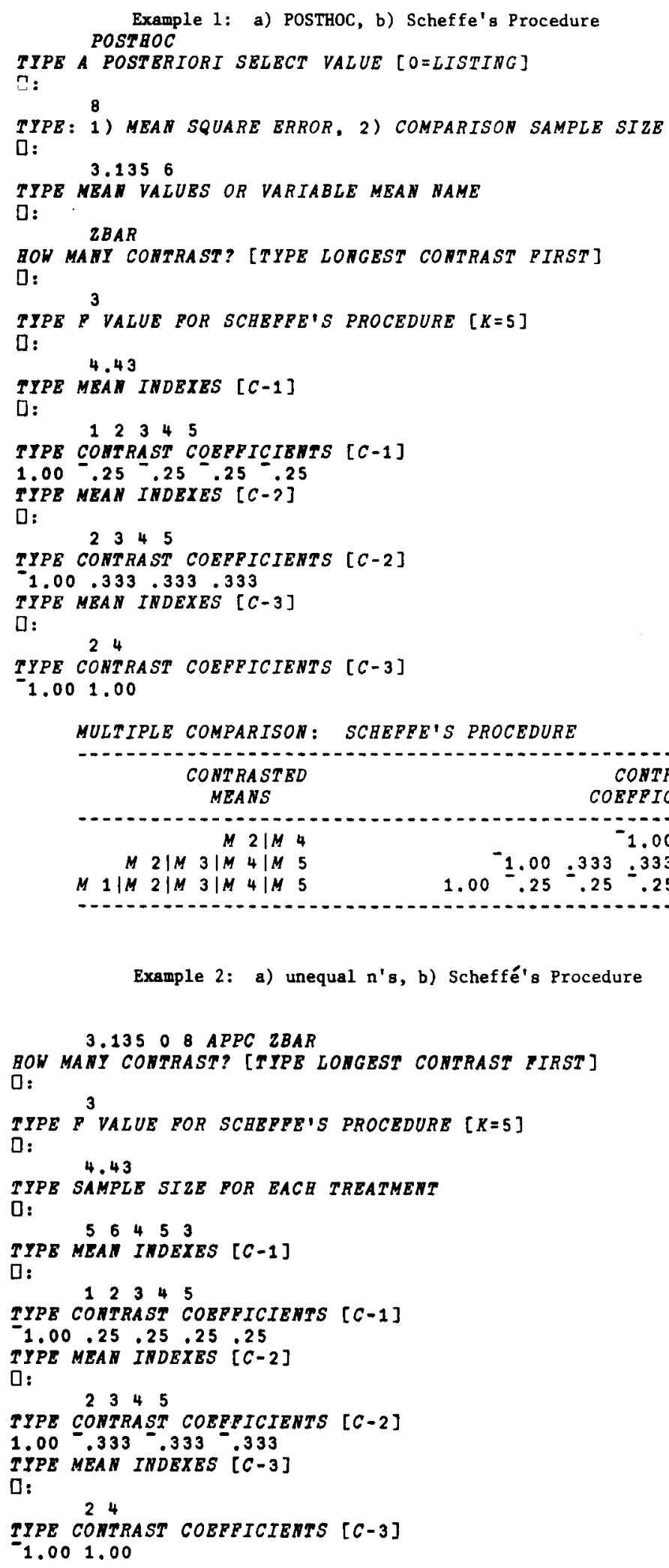


TABLE 5 (continued)

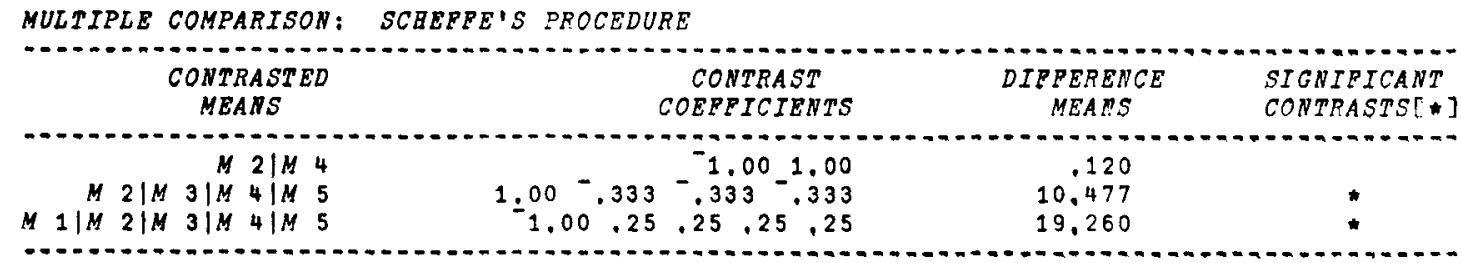

Example 3: a) Dunn's Procedure

$3.13569 A P P C \quad 2 B A R$

HOW MANY CONTRAST? [TYPE LONGEST CORTRAST RIRST]

ए:

3

TYPE T VALUE POR DUNN'S PROCEDURE [C=3]

[:

2.61

TYPE MEAN INDEXES [C-1]

[]:

12345

TYPE CORTRAST COEFFICIENTS [C-1]

$-1.00 \cdot 25 \quad .25 \quad .25 \cdot 25$

TYPE MEAN IRDEXES [C-2]

Q:

$234 \quad 5$

TIPE COHTRAST COERPICIENTS [C-2]

$1.00=.333-.333-.333$

TYPE MEAN IIIDEXES [C-3]

Q:

24

TYPE CORTRAST COEFFICIENTS [C-3]

$-1.001 .00$

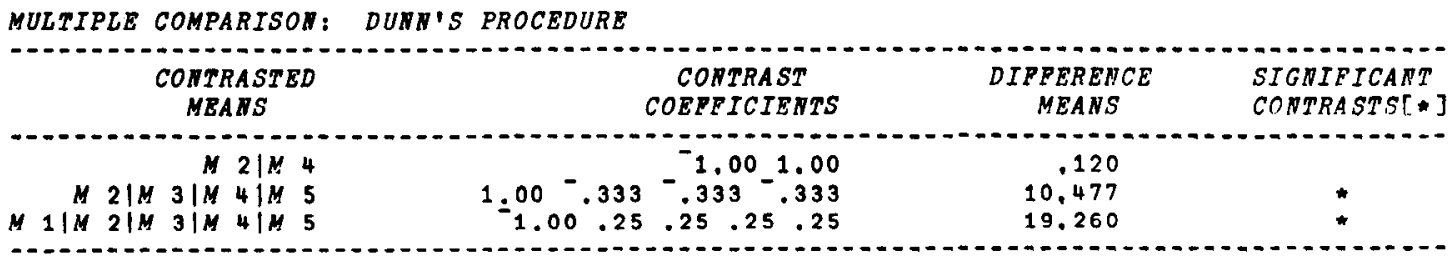

pairwise mean contrasts within vector ZBAR; the second provides the difference between each pair of means. If there are no significant contrasts among all possible paired means, the table is empty. For illustrations of fns APPC, see Table 4.

Function 4: ANPC. Fns ANPC is used when; (1) the a posteriori comparisons are nonpairwise [Scheffe's procedure (Test 8 ) is most appropriate];(2) the number of contrasts is small compared to the number of means in the experiment [Dunn's procedure (Test 9) is most appropriate] ; and (3) the ns are unequal across treatment levels (either Scheffe's or Dunn's procedure may be used) (Kirk, 1968). Only computational differences exist between the a posteriori tests in fns ANPC and similar tests in fns APPC. These differences exist in order to "handle" unequal ns and user-determined contrast coefficients.

Fns ANPC has the same left (NP) and right (ZBAR) arguments as fns APPC. The only difference is that the select value is not the same (i.e., Scheffe $=8$, Dunn $=9$ ). All analyses and outputs are done within fns ANPC.
Thus, fns ANPC can be used independently or in combination with fns POSTHOC.

There are four or five Qs in fns ANPC: (1) Q-1 requests the total number of contrasts desired; (2) Q-2a requests the $\mathrm{n}$ for each treatment level given that $\mathrm{NP}(2)=0$ (user-determined sample size), Q-2b the F (Scheffe's procedure) or t'D (Dunn's procedure) value; (3) Q-3, the indices of the means involved in the contrast; (4) Q4, the appropriate contrast coefficients. Tables are entered ( $F$ or $\left.t^{\prime} D\right)$ with degrees of freedom for the appropriate error term and either the number of treatment levels, $k(k=$ total number of means in ZBAR) - 1 for Scheffe's, or the number of contrasts, $c(c=$ number of contrasts specified in Q-1), for Dunn's procedure.

Fns ANPC loops iteratively through Qs, Q-3, and Q-4 until the number of user-selected contrasts is reached. Output, upon loop termination, is immediate. Output is in the form of a table which gives for each contrast: (1) the means involved in the contrast, (2) the respective contrast coefficients, (3) the differences between all means contrasted, and (4) the significance of the con- 
trast, if any. Significance for a particular contrast is indicated by an asterisk $(*)$. For illustrations of fns ANPC, see Table 5.

Computer. All functions were developed on an IBM 370/168 under APL/SV.

Note Added in Proof. After submission of the present manuscript, we discovered that the computer facilities at a number of institutions (including our own) have been updated (VS APL). To make the program we have described compatible with VS APL, monadic format and catenation must be used rather than semicolons to intermix character and numeric parts of expressions. A revised and extended version of the program is available from William T. McGowan, Behavioral Pharmacology Laboratory, Department of Psychology, University of South Carolina, Columbia, South Carolina 29208.

\section{REFERENCES}

Hays, W. L Statistics for the social sciences (2nd ed.). New York: Holt, Rinehart, \& Winston, 1973.

KIRK, R. E. Experimental design: Procedures for the behavioral sciences. Belmont, Calif: Brooks/Cole, 1968.

Lindquist, E. F. Design and analysis of experiments in psychology. Bosron: Houghton Mifflin, 1956.

McGowan, W. T. III, \& APpel, J. B. An APL program for calculating signal detection indices. Behavior Research Methods \& Instrumentation, 1977, 9, 517-521.

Ryan, T. A. The experiment as the unit for computing rates of error. Psychological Bulletin, 1962, 59, 301-305.

$\mathrm{W}_{\mathrm{INER}}$, B. J. Statistical principles in experimental design (2nd ed.). New York: McGraw-Hill, 1971.

(Accepted for publication September 13, 1977.) 